Nicki Dowling ORCID iD: 0000-0001-8592-2407

Stephanie Aarsman ORCID iD: 0000-0001-5457-4892

\title{
Brief Report: Problem gambling in international and domestic university students
}

\author{
Associate Professor Nicki A Dowling, $\mathrm{PhD}^{1,2}$ \\ Dr Meredith Brown, DPsych (Clinical) ${ }^{3}$ \\ Stephanie Aarsman ${ }^{1}$ \\ Dr Stephanie S Merkouris, $\mathrm{PhD}^{1}$ \\ ${ }^{1}$ School of Psychology, Deakin University, Geelong, Victoria, Australia \\ ${ }^{2}$ Melbourne Graduate School of Education, University of Melbourne, Victoria, \\ Australia \\ ${ }^{3}$ School of Psychological Sciences, Monash University, Victoria, Australia \\ Running head: Problem gambling in international and domestic students \\ Corresponding Author: $\quad$ Associate Professor Nicki A Dowling, PhD \\ Mailing address: Deakin University \\ Melbourne Burwood Campus \\ School of Psychology Building BC, Room BC5.116 \\ 221 Burwood Highway, Burwood \\ Melbourne, Victoria 3125
}

Telephone: $\quad+61(3) 92445610$

This is the author manuscript accepted for publication and undergone full peer review but has not been through the copyediting, typesetting, pagination and proofreading process, which may lead to differences between this version and the Version of Record. Please cite this article as doi: 10.1111/ajad.12981.

This article is protected by copyright. All rights reserved. 
Fax: $\quad+61(3) 92446858$

Email: nicki.dowling@deakin.edu.au

Number of words in abstract: 156

Number of words in narrative: 2259

Number of tables: 1

Number of figures: 0

Number of references: 12

\begin{abstract}
Background and Objectives

International students comprise an ethnic minority sub-population who may be at increased risk for the development of gambling problems. This study aimed to explore the psychosocial factors associated with gambling problems in international and domestic university students in Australia.

Methods

173 university students (127 domestic, 45 international) completed measures of gambling participation, problem gambling, psychosocial factors (depression, anxiety, perceived social support, loneliness, gambling-related cognitive distortions) and English language difficulties.

Results

Gambling participation, but not problem gambling status, was lower in international than domestic students. Only anxiety and cognitive distortions were associated with problem gambling in domestic students; and only cognitive distortions were associated with problem gambling in international students. International student status failed to moderate the relationships between any psychosocial factor and problem gambling status.
\end{abstract}

This article is protected by copyright. All rights reserved. 
Conclusions and Scientific Significance

Future research is required to elucidate problem gambling risk and protective factors in this ethnic minority sub-group, with a view to guide culturally-sensitive initiatives.

Keywords: Gambling; Problem gambling; International students; Psychosocial

\section{Problem gambling in international and domestic university students}

The development of gambling problems is associated with a range of psychosocial factors, including depression, anxiety, reduced social support, loneliness, and gambling-related cognitive distortions [1-3]. Cultural factors, including beliefs and values of a cultural group, the process of acculturation, and culturally determined help-seeking behaviours, also appear to play a role in the development of problem gambling [4]. Despite limited evidence, members of ethnic minorities in Australia tend to display lower levels of gambling participation, but heightened levels of problem gambling, compared to the general community [4]. Moreover, psychosocial problems, such as depression, anxiety, and loneliness related to adaptation problems have been cited among immigrants to Australia as common reasons for gambling [4]. The effects of culture are pervasive and may influence the intensity of gambling cognitive distortions [5]. Eastern ideas concerning luck, fate and the role of gambling are very different to western conceptualizations [5]. For example, there is evidence that compared to Caucasian gamblers, Chinese gamblers have more profound beliefs regarding illusion of control and a perceived inability to stop gambling, which are linked to specific Chinese cultural beliefs, values, and societal expectations [6].

International students comprise one ethnic minority sub-population who may be at an increased risk for developing gambling problems [7]. In addition to the typical transitions to adulthood and adjustments to university life, international students experience stressors relating to adjusting to a new country and culture [7].

This article is protected by copyright. All rights reserved. 
This may involve leaving behind family and friends, navigating financial and accommodation issues, English language proficiency expectations, and family pressure to achieve high academic achievement [8]. It is therefore not surprising that many international students experience a variety of problems whilst studying away from home compared to their domestic student counterparts, such as homesickness, reduced social support, depression, and anxiety [7]. These stressors can be coupled with a sudden exposure to a high-access gambling culture and access to large sums of money designated for living expenses [7].

Surprisingly, only one study internationally has investigated problem gambling among international students compared to domestic students [7]. In a sample of 1600 university students (836 domestic, 764 international) in Australia, domestic students reported a higher past-year frequency of gambling across 12 gambling activities than international students. Specifically, while international students were significantly more likely to play bingo and internet electronic gaming machines (EGMs), they were significantly less likely to gamble on horse/dog racing, lottery or instant scratch tickets, casino table gambling, and venue EGMs. Although not significantly different, male (9.7\%) and female (3.9\%) international students displayed high rates of problem gambling compared to male (7.8\%) and female (2.4\%) domestic students. While this study found that international students scored significantly higher than domestic students on depression and anxiety, it failed to explore the interaction of these psychosocial factors with international student status on problem gambling. Studies have revealed that international student status moderates the relationship between psychosocial factors and alcohol use [9], which has important implications for the identification of psychosocial factors that differentially influence the development of addictive behaviours in international and domestic students.

This article is protected by copyright. All rights reserved. 
An enhanced understanding of the psychosocial factors that play a role in gambling problems in international students could enhance the development of culturally-sensitive prevention and treatment practices. The study aim was to explore psychosocial factors associated with problem gambling in international and domestic university students in Australia. It was hypothesised that: (1) international students would display lower gambling participation, but higher rates of problem gambling, than domestic students; (2) psychosocial factors (depression, anxiety, social support, loneliness, and gambling-related cognitive distortions) would be associated with international student status; (3) psychosocial factors would be associated with problem gambling status for both international and domestic students but that international student status would moderate the relationships between psychosocial factors and problem gambling status; and (4) English language difficulties (as a proxy for acculturation difficulties) would predict problem gambling status in international students.

\section{Method}

\section{Participants and procedure}

Participants comprised 173 Victorian university students (127 domestic, 45 international) who completed an online or hard-copy survey in the English language (Table 1). International students, who generally came from dissimilar cultures with limited gambling availability, were roughly representative of international students in higher education in Victoria [10], nearly three-quarters of whom are from China, India, Malaysia, Indonesia, Hong Kong, and Singapore. Their countries of origin (countries in which they had spent the majority of their time before coming to Australia) were: Malaysia (17.8\%), Indonesia (17.8\%), China (13.3\%), Singapore (13.3\%), United States (6.7\%), India (4.4\%), and Canada (4.4\%), with single

This article is protected by copyright. All rights reserved. 
participants from Israel, Japan, Korea, Mauritius, Mexico, Oman, Qatar, South Korea, Sri Lanka, and United Arab Emirates. They had been living in Australia for 20.8 months $(\mathrm{SD}=18.1)$ and spent an average of 14.5 years $(\mathrm{SD}=11.25)$ in their country of origin before coming to Australia. Because they displayed a more similar problem gambling and psychosocial profile to domestic students, domestic students born overseas were included in the domestic student group. This small group of participants had resided in Australia for 12.2 years ( $\mathrm{SD}=6.7$ ). Study was the reason for coming to Australia for the majority of international students (95.6\%) but only a small proportion of domestic students born overseas (15.4\%). The majority of international students were full-fee paying students (93.3\%) compared to a small proportion of domestic students born overseas (19.2\%). Advertisements were placed around campuses and in electronic university newsletters, and students on university campuses were directly invited to participate. Ethical clearance was obtained from Monash University and RMIT University Human Research Ethics Committees. Table 1 [insert here]

\section{Measures}

Participants were classified into one of two groups (domestic and international students) according to their responses on the question: 'Would you consider yourself an international student?' Participants indicated their past six-month participation on multiple gambling activities: instant scratch tickets, sports betting, on-course horse/dog race betting, off-course horse/dog race betting, online/internet gambling, casino table games, bingo, lotteries, EGMs, other. Past-year gambling was classified into non-problem gambling (score=0), low-risk gambling (score=1-2), moderate-risk gambling (score=3-7), and problem gambling (scores=8-27) categories using the 9item Problem Gambling Severity Index. The PGSI displays high internal consistency

This article is protected by copyright. All rights reserved. 
(Cronbach $\alpha=.84$ ) and correlates well with other measures of problem gambling such as the South Oaks Gambling Screen and the DSM-IV-J.

Past-week depression and anxiety were measured using the 7-item Depression and Anxiety Subscales of the Depression Anxiety Stress Scale [DASS-21]. These subscales display excellent internal consistency (Cronbach's $\alpha=.97$ and .92 , respectively) and are strongly correlated with the Beck Depression Inventory and the Beck Anxiety Inventory, respectively. Perceived social support was measured using the12-item Multidimensional Scale of Perceived Social Support [MSPSS], which has good internal consistency (Cronbach's $\alpha=.88$ ) and has been shown to be negatively correlated with measures of anxiety and depression. Past-month loneliness was measuring using the 4-item Loneliness subscale of the Utrecht Homesickness Scale (UHS), which displays good internal consistency (Cronbach's $\alpha=.88$ ) and is highly positively correlated with other measures of loneliness and negatively correlatd with measures of social connectedness, satisfaction with life, and social support. Gamblingrelated cognitive distortions were measured using the Gamblers’ Beliefs Questionnaire (GBQ), which measures illusion of control and luck/perseverence. The GBQ subscales display excellent internal consistency (Cronbach's $\alpha=.90$ for Luck/Perseverance and .84 for Illusion of Control) and significantly higher GBQ scores are reported by problem gamblers than non-problem gamblers. Englishlanguage difficulties (as a proxy for acculturation difficulties) were measured using the 6-item English language difficulties subscale of the Inventory of Student Adjustment Strain (ISAS-E), which displays good internal consistency (Cronbach's $\alpha$ $=.86)$ and is negatively correlated with measures of self-concept.

This article is protected by copyright. All rights reserved. 


\section{Data Analysis}

Stata (v.15) was employed for data cleaning and analyses. For the small amount of missing data (less than 5\%), person mean substitution was used for scales with less than $30 \%$ missing data. Pairwise deletion was applied to cases with more than $30 \%$ of missing data. One observation was dropped due to missing international student status. PGSI scores were categorised into an ordinal variable (non-problem, low-risk, moderate-risk/problem) due to a non-normal distribution and small proportion of problem gamblers. International student status was regressed on to gambling participation (logistic regression) and PGSI problem gambling status (ordinal logistic regression). International student status was regressed on to each psychosocial factor in a series of univariate linear regression analyses employing a robust estimator (due to skewed data). A series of Spearman's correlations were employed to explore the association between PGSI problem gambling scores (continuous) and each psychosocial factor in both domestic and international student groups. A series of moderated ordinal logistic regressions was conducted to explore the degree to which international student status moderated the relationship between each psychosocial factor and PGSI problem gambling status. Finally, an ordinal logistic regression was conducted to investigate the relationship between ISAS-E English language difficulties and PGSI problem gambling status in international students. All analyses (except correlations) were adjusted for gender.

\section{Results}

International students were significantly less likely than domestic students to gamble in the previous six months ( $\mathrm{OR}=0.31, p=0.003)$, specifically on EGMs $(\mathrm{OR}=0.16, p=0.015)$; but international student status did not significantly predict PGSI problem gambling status ( $\mathrm{OR}=1.40, p=0.53)$ (Table 1$)$. International student

This article is protected by copyright. All rights reserved. 
status significantly predicted DASS anxiety $(\beta=0.27, \mathrm{p}=0.004)$, MSPSS social support $(\beta=-0.18, \mathrm{p}=0.024)$, UHS loneliness $(\beta=0.19, \mathrm{p}=0.015)$, and GBQ luck/perseverance $(\beta=0.19, \mathrm{p}=0.044)$. PGSI problem gambling severity was significantly positively associated with DASS anxiety $(\rho=0.24, p=0.008)$, GBQ illusion of control $(\rho=0.43$, $\mathrm{p}<0.001)$, and GBQ luck/perseverance $(\rho=0.39, \mathrm{p}<0.001)$ in domestic students; and GBQ illusion of control $(\rho=0.34, p=0.027)$ and GBQ luck/perseverance $(\rho=0.40$, $\mathrm{p}=0.007$ ) in international students. International student status failed to moderate the relationships between any psychosocial factor and PGSI problem gambling status (Table 1). English language difficulties did not significantly predict PGSI problem gambling status in international students $(\mathrm{OR}=0.94, p=0.10)$.

\section{Discussion}

This study aimed to enhance our understanding of gambling problems in international and domestic students. Compared to domestic students, international students were significantly less likely to gamble, particularly in relation to EGMs, suggesting that cultural beliefs and values can determine preferences for different types of gambling [4]. While statistically non-significant, international students were nearly three times more likely to be classified in the moderate-risk/problem gambling category and nearly half as likely to report low-risk gambling. The rate of moderaterisk/problem gambling of $9 \%$ in this international student sample is considerably higher than national estimates (2.3-4.3\%) [11, 12]. Taken together, these findings are generally consistent with the conclusion that individuals from ethnic minorities in Australia, including international students, display lower levels of gambling participation but increased levels of problem gambling [4, 7]. Confirmation of these trends in larger and more representative samples of Australian university students may suggest that culturally-sensitive gambling prevention and intervention initiatives for

This article is protected by copyright. All rights reserved. 
international students, regardless of their level of gambling participation, are warranted.

This is the first study to explore the role of international student status in the association between psychosocial factors and gambling problems. Consistent with previous literature [7], this study found that international students comprise a vulnerable group in terms of anxiety, perceived social support, loneliness, and luck/perseverance cognitive distortions, relative to domestic students. Unexpectedly, only anxiety and cognitive distortions were significantly associated with problem gambling in domestic students while only cognitive distortions were significantly associated with problem gambling in domestic students, suggesting that it may be important to address similar factors in these two student groups. Moreover, international student status failed to moderate the relationship between any psychosocial factor and problem gambling status and English language difficulties failed to predict problem gambling in international students. Taken together, these findings suggest that while international students may display acculturative adaptation problems as a result of studying away from home, these do not seem to differentially influence their rates of problem gambling. This is surprising, given evidence that these factors have been cited among immigrants as common reasons for gambling [4]. Of course, there may be other factors, both risk and protective, that are associated with the development of problem gambling in international students. Future research is required to investigate the role of both risk and protective factors in the development of international student problem gambling [2].

The findings of this study must be interpreted in the context of several limitations. The first predominately pertains to sample size. The lack of significant relationships, in particular moderating relationships, may be a result of the relatively

This article is protected by copyright. All rights reserved. 
small sample, particularly in relation to international students. Relatedly, because problem gambling is a low-base rate disorder, there was a need to merge the moderate-risk and problem gamblers in the current analyses. The small sample also precluded sub-analyses of domestic students born overseas or according to sociocultural factors such as gambling accessibility and individualistic versus collectivist cultures. Second, although international students must achieve a competent to proficient standard on English language proficiency tests to qualify for tertiary study in Australia, international students with poor English may have been underrepresented and the validity of the responses of the international students who did participate may have been affected. This is because, in this study, English language difficulties was employed as a relatively poor proxy for acculturation difficulties, which may be confounded by the fact that the self-report survey was conducted in English. Finally, this study sample was not representative, so conclusions on the estimates of gambling participation and problems should be interpreted with caution.

In summary, this study indicated that although international students show significantly lower levels of gambling participation, there is trend towards higher levels of problem gambling. While international students comprised a vulnerable group, only gambling-related cognitive distortions were associated with problem gambling in international students and international student status failed to moderate the relationships between any psychosocial variable and problem gambling. Further research in larger samples is required to elucidate the role of risk and protective factors in the development of problem gambling in international students to inform the development of culturally-sensitive gambling prevention and intervention initiatives for this ethnic minority sub-group.

This article is protected by copyright. All rights reserved. 


\section{Declaration of interest statement:}

The authors have no conflicts of interest to declare in relation to this article. The authors' three-year conflict of interest statement is as follows: ND and SM have received funding from multiple sources, including government departments and the Victorian Responsible Gambling Foundation (through hypothecated taxes from gambling revenue), as well as the National Association for Gambling Studies (NAGS), a not-for-profit organisation with individual members across all stakeholder groups, which derives its funding from member fees and conference proceeds. SM has been the Victorian state representatives (unpaid) on the NAGS Executive Committee (which includes representatives from all stakeholder groups). None of the authors have knowingly received research funding from the gambling industry or any industry-sponsored organization.

\section{References}

1. Dowling NA, Cowlishaw S, Jackson AC, Merkouris SS, Francis KL, Christensen DR. Prevalence of psychiatric co-morbidity in treatment-seeking problem gamblers: A systematic review and meta-analysis. Australian \& New Zealand Journal of Psychiatry. 2015, 49(6):519-539.

2. Dowling NA, Merkouris SS, Greenwood CJ, Oldenhof E, Toumbourou JW, Youssef GJ. Early risk and protective factors for problem gambling: A systematic review and meta-analysis of longitudinal studies. Clinical psychology review. 2017,51:109-124.

3. Johansson A, Grant JE, Kim SW, Odlaug BL, Gotestam KG. Risk factors for problem gambling: A critical literature review. Journal of Gambling Studies. 2009,25(1):67-92.

This article is protected by copyright. All rights reserved. 
4. Raylu N, Oei TP. Role of culture in gambling and problem gambling. Clinical Psychology Review. 2004,23:1087-1114.

5. Papineau E. Pathological gambling in Montreal's Chinese community: An anthropological perspective. Journal of Gambling Studies. 2005,21(2):157178.

6. Oei TP, Lin J, Raylu N. The relationship between gambling cognitions, psychological states, and gambling: A cross-cultural study of Chinese and Caucasians in Australia. Journal of Cross-Cultural Psychology. 2008, 39(2):147-161.

7. Moore SM, Thomas AC, Kale S, Spence M, et al. Problem gambling among international and domestic university students in Australia: who is at risk? Journal of Gambling Studies. 2013, 29(2):217-230.

8. Yi JK, Lin JCG, Jenny K, Kishimoto Y. Utilization of counseling services by international students. Journal of Instructional Psychology. 2003, 30(4):333342.

9. Yeh JC, Hsu SH, Mittman AJ, Litt D, Geisner IM. Understanding differences in alcohol consumption and depressed mood between U.S.- and foreign-born Asian and Caucasian college students. Journal of Ethnicity in Substance Abuse. 2017, 15(2):160-175.

10. Australian Government Department of Education. International student data. Available: https://internationaleducation.gov.au/research/international-studentdata/pages/default.aspx

11. Dowling NA, Cowlishaw S, Jackson AC, Merkouris SS, Francis KL, Christensen DR. Prevalence of psychiatric co-morbidity in treatment-seeking

This article is protected by copyright. All rights reserved. 
problem gamblers: A systematic review and meta-analysis. Australian \& New Zealand Journal of Psychiatry. 2015, 49(6):519-539.

12. Gainsbury SM, Russell A, Hing N, Wood R, et al. The prevalence of problem gambling in Australia: Assessing the impact of interactive gambling and new technologies. Psychology of Addictive Behaviors. 2014, 28(3):769.

Table 1. Sample Description and Role of Psychosocial Factors in International Student Problem Gambling

\begin{tabular}{|c|c|c|c|}
\hline Demographic characteristics & $\begin{array}{l}\text { Domestic } \\
\text { Students }\end{array}$ & $\begin{array}{l}\text { International } \\
\text { students }\end{array}$ & $\begin{array}{c}\text { Total } \\
\text { sample }\end{array}$ \\
\hline Gender (male, \%) & 33.1 & 33.3 & 33.1 \\
\hline Age $(\mathrm{M}, \mathrm{SD})$ & $22.6(6.0)$ & $22.3(3.8)$ & $22.5(5.5)$ \\
\hline Marital Status (single, \%) & 53.5 & 64.4 & 56.4 \\
\hline \multicolumn{4}{|l|}{ Country of birth (\%) } \\
\hline Australia & 80.3 & $2.2^{\mathrm{c}}$ & 59.9 \\
\hline Indonesia & 1.6 & 20.0 & 6.4 \\
\hline Malaysia & 1.6 & 15.6 & 5.2 \\
\hline China & 3.2 & 13.3 & 5.8 \\
\hline Singapore & 0.8 & 13.3 & 4.1 \\
\hline India & 0.0 & 6.7 & 4.1 \\
\hline United States & 0.8 & 6.7 & 2.3 \\
\hline South Korea & 0.0 & 4.4 & 1.6 \\
\hline Other & 11.8 & $17.8^{\mathrm{d}}$ & 13.4 \\
\hline \multirow[t]{2}{*}{ Enrolment (full-time, \%) } & 89.8 & 97.7 & 91.8 \\
\hline & $\begin{array}{l}\text { Domestic } \\
\text { Students }\end{array}$ & $\begin{array}{l}\text { International } \\
\text { students }\end{array}$ & $\begin{array}{l}\text { Odds } \\
\text { ratio }\end{array}$ \\
\hline Gambling participation (\%) & 48.0 & 22.2 & $0.31 * *$ \\
\hline Instant scratch tickets & 17.6 & 11.4 & 0.60 \\
\hline Sports betting & 12.0 & 2.3 & 0.15 \\
\hline On course betting & 8.8 & 0 & 1 \\
\hline Off course betting & 6.5 & 0 & 1 \\
\hline Online gambling & 7.2 & 2.3 & 0.29 \\
\hline Casino table games & 20.0 & 13.6 & 0.61 \\
\hline Bingo & 1.6 & 0 & 1 \\
\hline Lotteries & 11.3 & 9.1 & 0.78 \\
\hline Electronic gaming machines & 23.2 & 4.6 & $0.16^{*}$ \\
\hline Other & 2.1 & 2.6 & 1.41 \\
\hline PGSI Problem gambling status & & & 1.40 \\
\hline Non-problem gambling & 89.6 & 86.4 & \\
\hline Low-risk gambling & 7.2 & 4.6 & \\
\hline Moderate-risk/problem gambling & 3.2 & 9.0 & \\
\hline $\begin{array}{l}\text { Prediction of psychosocial factors by } \\
\text { international study status }{ }^{\text {a }}\end{array}$ & $\mathrm{B}$ & Robust SE & $\beta$ \\
\hline
\end{tabular}

This article is protected by copyright. All rights reserved. 


\begin{tabular}{|c|c|c|c|}
\hline DASS-D Depression & 1.89 & 1.84 & 0.08 \\
\hline DASS-A Anxiety & 4.16 & 1.42 & $0.27 * *$ \\
\hline MSPSS Social support & -0.43 & 0.19 & $-0.18^{*}$ \\
\hline UHS Loneliness & 1.47 & 0.60 & $0.19 *$ \\
\hline GBQ Illusion of control & 0.50 & 1.85 & 0.02 \\
\hline GBQ Luck/perseverance & 4.51 & 2.23 & $0.19 *$ \\
\hline $\begin{array}{l}\text { Interactions between psychosocial factors \& } \\
\text { international student status on problem } \\
\text { gambling }^{\text {a,b }}\end{array}$ & $\begin{array}{l}\text { Odds } \\
\text { ratio }\end{array}$ & Robust SE & 95\% CIs \\
\hline DASS-D Depression x Student status & 1.00 & 0.05 & $0.91,1.11$ \\
\hline DASS-A Anxiety x Student status & 0.95 & 0.05 & $0.85,1.05$ \\
\hline MSPSS Social support x Student status & 1.00 & 0.42 & $0.44,2.29$ \\
\hline UHS Loneliness x Student status & 1.22 & 0.16 & $0.94,1.57$ \\
\hline GBQ Illusion of control x Student status & 0.97 & 0.05 & $0.88,1.06$ \\
\hline GBQ Luck/perseverance x Student status & 0.98 & 0.04 & $0.91,1.05$ \\
\hline \multicolumn{4}{|c|}{$\begin{array}{l}\text { a Adjusted for gender } \\
{ }^{\mathrm{b}} \text { Reference category for the dependent variable = non-problem gambling } \\
\text { c One international student identifying Chinese ethnicity reported they were born in Australia but had } \\
\text { resided in Australia for only } 3 \text { years } \\
{ }^{d} \text { Country of birth reported by single international students: Canada, Israel, Japan, Mauritius, Mexico, } \\
\text { Oman, Sri Lanka, and United Arab Emirates } \\
{ }^{*} p<0.05, * * p<0.01\end{array}$} \\
\hline
\end{tabular}

This article is protected by copyright. All rights reserved. 


\section{University Library}

\section{- M M N E R VA A gateway to Melbourne's research publications}

Minerva Access is the Institutional Repository of The University of Melbourne

Author/s:

Dowling, NA;Brown, M;Aarsman, S;Merkouris, SS

Title:

Brief Report: Problem Gambling in International and Domestic University Students

Date:

2019-12-03

Citation:

Dowling, N. A., Brown, M., Aarsman, S. \& Merkouris, S. S. (2019). Brief Report: Problem Gambling in International and Domestic University Students. AMERICAN JOURNAL ON ADDICTIONS, 29 (1), pp.77-81. https://doi.org/10.1111/ajad.12981.

Persistent Link:

http://hdl.handle.net/11343/286708 